\title{
Influence of Household Behaviour on Malaria Control in Zamfara State North West Nigeria: A Pilot Study for Instruments Validation
}

\author{
Ahmad Yahaya Maigemu \\ School of Government, College of Law Government and International Studies, Universiti Utara Malaysia \\ Email: ahmad95084@gmail.com \\ Dr. Kalthum Bt Haji Hassan \\ School of Government, College of Law Government and International Studies, Universiti Utara Malaysia \\ Email: Kalthum@uum.edu.my
}

Doi:10.5901/mjss.2015.v6n3s2p183

\section{Abstract}

Malaria in Nigeria and Africa remains most important health problem. It remains a vital public health fear of our time. Human behaviour is a tremendous challenge that must be addressed if malaria control and ultimately elimination is to be successful. This study was aimed to measure the validity and reliability of instruments of household behaviour on malaria control. The reliability of each construct is determined using Cronbach's Alpha statistics. The Cronbach's Alpha results provide evidence and good acceptable value that indicates the instruments were sufficiently valid and reliable.

Keywords: malaria control, household, behaviour, influence, instruments validation, Zamfara state, Nigeria.

\section{Introduction}

Malaria in Nigeria and Africa remains most important health problem. It remains a vital public health fear of our time. According to Olusegun (2012), malaria prevalent causes frequent suffering to human society and influences tremendously, unkind and gigantic burden on human population. It has been stated that out of the more than one million deaths caused by malaria worldwide, $90 \%$ take place in sub-Saharan Africa (WHO, 2012). World Health Organization (2012) and World Bank (2009) stated that malaria disturbs 3.3 billion persons equivalent to half of global population.

Similarly, Nigeria carries the greatest burden and consequences of malaria epidemic among countries in the world (Ajala \& Wilson, 2013; Garley et al., 2013; WHO, 2010). Nigeria with population of over 140 million people according to 2006 census, almost everyone in the country is at risk for malaria transmission except the minority (NPC and ICF Macro 2008). According to National Malaria Control Program in Nigeria (2005), malaria is the major cause of morbidity and mortality, especially among children below age of five. In Nigeria alone, malaria is the causes of over $50 \%$ outpatient's attendance and $40 \%$ of hospital admissions, $30 \%$ of child mortality and $10 \%$ of maternal mortality (WHO 2012; WHO 2011; WHO 2010; FMH 2007).

Because of the seriousness of the problem World Health Organization (WHO), United Nation Children Fund (UNICEF), United Nation Development Program (UNDP) and World Bank (WB) have joined forces in universal malaria control effort with the intend of falling malaria mortality (WB, 2009; WHO, 2009). The effort of those joint forces and their organised anti malaria programmes could be conducted largely without reference to the behaviour and belief system of the human societies affected (Amzat, 2009). Therefore, the failure of those initiatives can often be blame on the lack of adequate consideration given to the human and behavioural aspect of malaria control. As a result human behaviour needs to be understood as a factor in malaria control.

The main reasons behind the requirement of validity and reliability of instruments of the influence of household behaviour on malaria control is the fact that human behaviour is a tremendous challenge that must be addressed if malaria control and ultimately elimination is to be successful. Malaria can be studied from a biological, human and sociocultural point of view, and indeed, considerable work has been done but with most weight given to the biological sphere (WHO, 2013; WHO, 2012; WHO, 2011). Thus considering the importance or link between human behaviour, health and its influences on successful health programs and initiatives through an understanding of human behaviour there is need therefore to explore the link between human behaviour and malaria control in order to provide new understanding of the 
link between human attitudes on household behaviour on fumigation, household behaviour on waste disposal and household perception on malaria disease and control.

\section{Literature Review}

In general for the most social scientists human behaviour is largely learned and well understands from other people. For social scientists way of life and human tradition, is most generally look upon as a cohesive set of ideas, beliefs and knowledge that live in an absolutely different realm to biology (Laland 2008). Researchers assumed culture is the main influence of human behaviour. Human behaviour in relation to health has been defined as any action embark on by a person consider himself to be healthy for the reason of preventing disease or detecting it at an asymptomatic stage (Laland 2008).

Godin and Kok (1996) define human health behaviour as obvious behavioural patterns, human behaviour and habits that relate to human health maintenance, to human health restoration and to human health development. $\mathrm{A}$ valuable broad meaning of human behaviour in relation to health would comprise any action undertaken for the purpose of preventing or detecting disease or for improving health and well being. A number of studies have looked at the relationship between the performance of human health behaviours and a variety of health outcomes. For example (Fredrickson et al 2013; Laland 2008; Godin \& Kok 1996). Such studies have demonstrated the importance of a variety of human behaviours for both morbidity and mortality. Research into the major causes of premature death in the western world (e.g. cancer) has emphasized the importance for prevention of behaviours such as smoking, alcohol consumption and sexual human behaviours (Laland 2008). Several authors (State et al 2013; Kim \& Hunter 1993) have pointed out that human health behaviours may have a positive impact on quality of life of human population.

\subsection{Malaria Control}

Malaria is one of the most important health problems that intimidate human survival today. The illness has been explained since before the middle age and still stayed as a significant health concern. The word 'malaria' comes from Italian, and literally means 'bad air' (Carter et al 2002). According to Azizi (2013), Joy et al (2003), Malaria has been among individuals since the dawn of time. Malaria in human beings has been well-known since the most prehistoric time of human existence (Hill 1992). The earliest confirmation account of what may have been malaria as a human disease is originated by Hippocrates around 2,700 BC. (Hill 1992). According to Alaba (2005) malaria is the sign of the illness of parasite of the plasmodium brand. It is a dwindling infectious syndrome characterized by chills, shaking and fever (Alaba 2005; Ault 1994; Hill, 1992).

Malaria is a worldwide pandemic disease which has engaged global concentration. The World Health Organization in 1985 submitted a motivated plan for the suppression of malaria globally at the World Health Assembly (WHO 2005). The enormous trouble of malaria all around the globe formed earlier attempt by certain social institutions (both formal and non-formal) on malaria administration (FMH 2005). In so many countries of the world provision of services was been tried in their attempt to control malaria. According to Satterthwaite (2003) in Panama 1878, that was than in part of Colombia there was an incidence of high yellow fever, malaria which was cause as a result of poor environmental conditions such as dirty street and improper sanitation (Satterthwaite 2003). This affected the productivity of workers in Panama Canal. Consequently environmental management was adopted as a key to malaria control, by drainage construction, infrastructure provision and other environmental facilities. As a result the prevalence of malaria reduced with greater proportion.

Not in Panama alone in the early $19^{\text {th }}$ century Malaysia applied environmental sanitation as strategy employed for the elimination of malaria. Watson (1921) demonstrated the importance of environmental modification by showing that selective clearing of the forest around the settlements could control the mosquito, which was result in the elimination of malaria. Bradley (1994) established that in 1901 Klang town and Port Swettenham in present day Malaysia witnessed a high series of malaria episode (Watson 1921). One of the burdens was that 50\% of the patient attending hospital and medical services in Malaysia had malaria (Bradley 1994). The strategy helps greatly in reducing the mortality rate caused by malaria in the country. After witnessed the progress and success of the approach, it was later applied to the other part of Malaysia (Bradley, 1994; Watson, 1921). This presents that successful malaria control have to target the reduction of mosquito. 


\subsection{Household Behaviour: Fumigation of Environment/Waste Water Disposal}

The consequence of the association connecting health and environment has been since recognized (Ityavyar \& Gusau 1990). This was chiefly observed in the circle of the previous century, by the influential contributions of Rene Dubos (1968), Thomas Mckeown (1976), John B. and Sonjo Mckinlay (1975) cited in Ityavyar and Gusau (1990). In their different conclusion, these intellectuals arrived at finding now generally acknowledged. According to them, human behaviour on environment has additional deep impact on the physical condition of individuals than modern medicine (Ityavyar \& Gusau 1990).

There are several other studies showing exact effects of certain environmental behaviour on morbidity and mortality in diverse settings. Owoeye and Omole (2012) carried out a study to examine health situation among slum dwellers in Akure, Nigeria. The result of the study shows that better human environmental management and their behaviours has impact on the physical condition of the people (Owoeye \& Omole 2012). Better environmental services are therefore providing a permanent solution to the health problem cause by deterioration from poor environment. This also shows a concrete relationship between disease such as malaria and human behaviour regarding how to handling their environment. In another study Owoeye (2012) confirm that environment, health and disease operate in a vacuum and they can see as related (Owoeye, 2012). It is therefore, believed that sanitation have a profound impact on the health of the society, since better environment with good services provision serves not conducive for disease like malaria. Owoeye and Omole (2012) further stated that poor environment is always accompanied with various diseases and ailment. Those diseases include malaria, typhoid fever and diarrhoea. The finding of this study also stated the connection between disease such as malaria and environmental services (Owoeye 2012; Owoeye \& Omole 2012).

Buttressing relationship between environmental sanitation and malaria, Haque et al (2010) conducted a study to investigate prevalence of malaria in endemic district of Bangladesh. The findings of the study shows that, environmental factors like pools of stagnant water, bushes, heaps of garbage and poor housing conditions encourage disease incidence (Haque et al 2010). The study also concludes that provision of adequate sanitation services that will make environment better will also significantly improved the quality of life and health status of the people. This is in line with Owoeye (2012) who stated that, the effect of environmental factors on incidence of malaria shows a highest malaria cases among children living in places around or surrounded by swamps and bushes. According to the studies (Haque et al 2010 and Owoeye 2012) reducing malaria transmission cases will be possible and might be achieved through appropriate environmental services such as improving drainage and the quality of housing structure (Haque et al 2010 and Owoeye 2012).

\subsection{Perception on Malaria}

It is important to look into the various signs and symptoms of malaria because it is through such signs and symptoms that people define and perceive malaria. People in different socio-geographical and cultural settings perceived different signs and symptoms of malaria. It is generally believed that based on perceived sign and symptom that people determine on what attitude they show in respect to health seeking behaviour. Our assumption is that knowledge about the symptoms of illness or disease is a major determinant of the health and should be a modifying factor for adequate measures that would be used to control the disease. This is supported by Das et al (2013) in his study among two districts of Odisha in India where he accessed people understanding and practices on malaria. It was discovered that common cold, typhoid, tuberculosis, skin disorders are among the signs and symptom of malaria in the community that study was carried out. In a related finding Gasasira (2003), conducted a study on comparative effective management of malaria in Kampala, Uganda of sub Saharan Africa. The study reveals that $65 \%$ of the respondent reported typhoid and tuberculosis as symptoms of malaria (Gasasira 2003). When people defined malaria based on its sign and symptom it means there is need also to know how their understanding influence their behaviour to reduce it further occurrences.

\subsection{Objective of the Study}

1. The objective of this study is identifying the validity and the reliability of influence of household behaviour on malaria control instrument (behaviour on fumigation, behaviour on waste disposal and household perception). 


\section{Methodology}

\subsection{Sample}

The current study is carried out among the household heads in Zamfara state North West Nigeria. The study comprises 40 respondents which among them 37 were male household heads while only 3 among the respondents are female household heads.

\subsection{Instruments}

Data of this study was collected using one instrument that contains 5 sections. Section 1 is on behaviour on fumigation, section 2 is on behaviour on waste disposal and section 3 is on household perception while section 4 is on malaria control and lastly section 5 is on demographic profile of the respondents. The instrument contains 87 items. Specifically behaviour on fumigation has 21 items, while behaviour on waste disposal has 38 items and perception has 18. Lastly malaria control has 10 items. The respondents were asking to respond on the questionnaire to indicate the extent to which they agreed or disagreed with the statement based on 5 likert scale. The 1-5 likert scales in the questionnaire represent strongly disagree, disagree, neutral, agree and strongly agree respectively.

Section one of the questionnaire contained 21 items was used to measure the influence of fumigation of environment to malaria control and prevalence. The section 2 with 38 items in this questionnaire was used to measure the influence of household behaviour on waste disposal and malaria control. Section 3 and four contained 18 and 10 items respectively. They were used to measure the household perception on malaria and general behaviour on malaria control respectively.

\subsection{Data Analysis}

Data collected on this study was first entered into excel. The missing values were filled and then transfer to SPSS (Statistical Packages of Social Science). Therefore, SPSS version was used to analyze validity and reliability employing Cronbach's alpha and Pearson's coefficient correlation.

\subsection{Findings and Discussion}

Based on the data collected and objective of the research, the findings of this present study are presented to determined the validity and reliability of instrument

\subsubsection{Reliability Analysis}

Reliability is defined as the strength and reliability of the items used and it is one of the indicator of goodness of measure (Sekaran, 2003). Cronbach Alpha coefficient is used in this present study to find out the internal reliability of scaled items via the investigation of the average inter-item correlation. The Cronbach's alpha coefficients calculation was used in this study. According to Nunnally (1994) all Cronbach Alpha coefficients above 0.60 is believed to be good enough for item reliability. In this current research Cronbach's Alpha was the approach used to assess reliability of household behaviour influence on malaria control. The behaviour on fumigation scale consisted of 21 items and its Cronbach's alpha value is .900 (see Table 1), which is considered to be a satisfactory reliability.

Table 1: Fumigation behaviour Reliability Statistics

\begin{tabular}{|c|c|c|}
\hline Cronbach's Alpha & Cronbach's Alpha Based on Standardized Items & N of Items \\
\hline .898 & .900 & 21 \\
\hline
\end{tabular}

In respect of behaviour on waste disposal, the construct has the total number of 38 items. The results in that case established that the Cronbach's Alpha value based on standardized items is .832 which is considered good enough base on Nunnally (1994) recommendation. (See Table 2). 
Table 2. Behaviour on waste disposal reliability statistics

\begin{tabular}{|c|c|c|}
\hline Cronbach's Alpha & Cronbach's Alpha Based on Standardized Items & N of Items \\
\hline .834 & .832 & 38 \\
\hline
\end{tabular}

Similarly, household perception on malaria construct has the total number of 18 items. Cronbach's Alpha value based on standardized items shows the significance of .845 levels which is enough to justified acceptable level of validity and reliability as suggested by Nunnally (1994). See Table 3 for more clarification.

Table 3. Perception reliability statistics

\begin{tabular}{|c|c|c|}
\hline Cronbach's Alpha & Cronbach's Alpha Based on Standardized Items & N of Items \\
\hline .845 & .845 & 18 \\
\hline
\end{tabular}

In addition, general behaviour on malaria control latent construct has the number of 10 items in its totality. The reliability statistics reveals the Cronbach's Alpha value of .894 which is considered an acceptable value for testing reliability of instruments. Table 4 shades more light.

Table 4. Malaria control reliability statistics

\begin{tabular}{|c|c|c|}
\hline Cronbach's Alpha & Cronbach's Alpha Based on Standardized Items & N of Items \\
\hline .895 & .894 & 10 \\
\hline
\end{tabular}

However, this study also calculated the reliability statistics of all 87 items using the Cronbach's Alpha in the analysis based on standardized items. The results show the Cronbach's Alpha value of .921 with total number of 87 items (see Table 5). These convince that all items tested in this study have required validity and reliability based on Sekaran (2003) and Nunnally (1994) respectively.

Table 5. All items reliability statistics

\begin{tabular}{|c|c|c|}
\hline Cronbach's Alpha & Cronbach's Alpha Based on Standardized Items & N of Items \\
\hline .921 & .921 & 87 \\
\hline
\end{tabular}

\section{Conclusion}

In conclusion, the instruments validation and reliability statistics provided evidence of satisfactorily Cronbach's Alpha value for reliability requirement. Therefore, the reliability factor of all items assessed in this study was sufficiently and acceptably reliable and valid. Finally the items were good enough to provide information on the influence of household behaviour on malaria control. The findings regarding relationship between household behaviour instruments factors shows strong relationship between those factors. This finding concerning instruments for measuring household behaviour on malaria control provides information on how to achieve the objective of understanding the influence of household behaviour on malaria control. Furthermore, the findings will be useful as contribution to the additional knowledge that will be use to change policy or strategy on malaria control. The study will be important to policy makers: The World Health Organization (WHO), the Federal Ministry of Health (FMH), National Malaria Control Program (NMCP), non-governmental organization (NGOs) and other policy makers in the ways of malaria control activities.

\section{References}

Ajala, A. S., \& Wilson, N. A. (2013). Local aetiology and pathways to care in malaria among the Ibibio of south-coastal Nigeria. health, culture and society, 4(1). doi:10.5195/hcs.2013.102

Alaba, A. O. (2005). Malaria in children: Implication for the productivity of female caregivers in Nigeria. Selected paper for the 2005 
annual conference of the Nigerian economic society.

Amzat, J. (2009). Health inequality in Nigeria. In I.S. Ogundiya, A.O. Olutayo, \& J. Amzat (Eds.). A decade of redemocratization in Nigeria. Nigeria: Department of political science, Usmanu Danfodiyo University.

Ault, S.K. (1994). Environmental management: A re-emerging vector control Strategy. American journal for tropical medicine and hygiene, p. 35.

Azizi, M. H., \& Bahadori, M. (2013). Brief historical perspectives of malaria in Iran, 16(2), 131-135.

Bradley D.J., (1994) Swellengrebel and Species Sanitation: Environmental and Ecological Aspects. Parassitologin:137-47.

Carter R., Mendis K.N (2002). Evolutionary and historical aspects of the burden of malaria. Clin microbiol: 564-94.

Cresweel, J (2007). Qualitative, quantitative, and mixed methods approaches. Second edition

Das, A., Das Gupta, R. K., Friedman, J., Pradhan, M. M., Mohapatra, C. C., \& Sandhibigraha, D. (2013). Community perceptions on malaria and care-seeking practices in endemic Indian settings: Policy implications for the malaria control programme. Malaria journal, 12(1), 39. doi:10.1186/1475-2875-12-39

Federal Ministry of Health (2007). National integrated maternal, newborn and child health strategy. Federal government of Nigeria, 2007.

Federal ministry of health (2005). Roll back malaria baseline data for monitoring and evaluation. Abuja: Federal ministry of health, p. 30.

Fredriksen, B., \& Kagia, R. (2013). Attaining the 2050 Vision for Africa: Breaking the Human Capital Barrier. Global Journal of Emerging Market Economies, 5(3), 269-328. doi:10.1177/0974910113505794

Garley, A. E., Ivanovich, E., Eckert, E., Negroustoueva, S., \& Ye, Y. (2013). Gender differences in the use of insecticide- treated nets after a universal free distribution campaign in Kano State , Nigeria : post-campaign survey results, 1-7.

Gasasira, A. F., Dorsey, G., Nzarubara, B., Staedke, S. G., Nassali, A., Rosenthal, P. J., \& Kamya, M. R. (2003). Comparative efficacy of aminoquinoline-antifolate combinations for the treatment of uncomplicated falciparum malaria in Kampala, Uganda. The American journal of tropical medicine and hygiene, 68(2), 127-32.

Godin, G., and Kok, G. (1996). The theory of planned behaviour: A review of its applications to health related behaviours. American Journal of Health Promotion, 11, 87-98.

Haque U, Magashaes R.J, Reid H.L, Clements A.C, Ahmad S.M, Islam A, et al (2010). Spatial prediction of malaria prevalence in an endemic areas of Bangladesh. Malaria journal 9:120.

Hill, A.V.S. (1992). Malaria resistance genes: A natural selection. Transaction of the royal society of tropical medicine, p. 86.

Ityavyar D. A. and Gusau G.A. (1990). The state, health and environment in Nigeria.Un published

Joy D.A, Feng X, Mu J, Furaya T, Chotivanich K, Kretti A.U et al (2003). Early origin and recent expansion of plasmodium falciparum. Science 300 (5617): 318-21.

Kim, M., \& Hunter, J. E. (1993). Attitude-Behavior Relations : A Meta-Analysis of Attitudinal Relevance and Topic, 43(1).

Laland, K. N. (2008). Exploring gene-culture interactions: insights from handedness, sexual selection and niche construction case studies. Phil. Trans. R. Soc. B 363, 3577-3589. (doi:10.1098/rstb.2008.0132)

National Malaria Control Program in Nigeria (NMCP) (2005).Malaria: 2005 annual report. Abuja: Federal ministry of health and roll back malaria.

National Population Commission (NPC) [Nigeria] \& ICF Macro (2004).Nigeria Demographic and Health Survey 2008. Abuja: National Population Commission and ICT Macro.

Nunnaly, J.C., and Bernstein, I.H. (1994). Psychometric theory (3rd ed). New York: McGraw-Hill.

Olusegun, O. L., Thomas, R., \& Micheal, I. M. (2012). Curbing maternal and child mortality : The Nigerian experience, 4(April), 33-39. doi:10.5897/IJNM11.030

Owoeye J.O (2012). Slum formation in core residential neighborhood of Akure, Nigeria; Lambert Academic Planning (LAP), Germany. Available at: http://www.get-morebooks.com

Owoeye J.O and Omole F.K (2012). Build environmental delay and health situation of slum dwellers in residential core of Akure; American journal of human ecology, USA.

Satterthwaite, D. (2003). The Links between Poverty and the Environment in Urban Areas of Africa, Asia, and Latin America. The Annals of the American Academy of Political and Social Science, 590(1), 73-92. doi:10.1177/0002716203257095

State, C. R., Takon, J., Titus, E., Daniel, E., \& Amalu, C. A. (2013). Rjopes Rjopes assessment of local people's attitude towards natural resource conservation in BOKI local government area, 2(2), 60-66.

Watson, M. (1921). The prevention of malaria in the federated Malay states. A record of twenty years progress. London John Murray.

World Bank (2009). Nigeria malaria prevention program in Nigeria aims at universal bed net coverage.http://web.worldbank.org/ WBSITE/EXTERNAL/COUNTRIES/AFRICAEXT/NIGERIAEXTN/0,contentMDK:22178832-menuPK::368902-pagePK:2865066piPK:2865079-thesite PK:368896,00.html.

World Health Organization (2013). The Africa Summit on Roll Back Malaria. WHO/CDS/RBM/2000 17. Geneva: World Health Organization.

World Health Organization (2012). World Malaria Report Fact Sheet. World Health Organization.

World Health Organization (2011) Environment and health: Healthy environments for healthy people Available at:http://www.euro. who.int/en/what-we- do/health-topics/environment-and-health.

World Health Organization (2010). Global Report on Antimalarial Drugs Efficacy and Drugs Resistance: 200-2010. Geneva: World Health Organization.

World Health Organization (2009). Nigeria Country Profile. World Malaria Report, 2009. Geneva: WHO.

World Health Organization (2005). The Economic Burden of Malaria: Evidence from Nigeria. Nigeria: World Health Organization. 